\title{
Ineficácia de arranjos espaciais no controle da cercoporiose (Cercospora beticola) da beterraba
}

\author{
Leandro Luiz Marcuzzo ${ }^{1}$, Tatiana da Silva Duarte ${ }^{2}$, Antonio João Rosa Neto ${ }^{1}$, Maíra Elena Borges Costa ${ }^{3}$
}

\begin{abstract}
${ }^{1}$ Instituto Federal Catarinense - IFC/Campus Rio do Sul, CP 441, CEP 89.163-356, Rio do Sul, SC, toniajr@hotmail.com; ${ }^{2}$ Universidade Federal do Rio Grande do Sul - UFRGS, Faculdade de Agronomia, Departamento de horticultura e silvicultura, CP 15.100, CEP 91540-000, Porto Alegre, RS, tatiana.duarte@ufrgs.br; ${ }^{3}$ Epagri/EMVM, CEP 89148-000, Vitor Meireles, SC, mairacosta@epagri.sc.gov.br

Autor para correspondência: Leandro Luiz Marcuzzo (marcuzzo@ifc-riodosul.edu.br)

Data de chegada: 29/04/2015. Aceito para publicação em: 07/07/2015.
\end{abstract}

$10.1590 / 0100-5405 / 2093$

A cercosporiose da beterraba causada por Cercospora beticola é a principal doença da beterraba. Os sintomas característicos são manchas circulares com margem purpúrea e centro claro e à medida que aumentam ficam com tonalidade acinzentada, porém com a necrose, o tecido lesionado cai e a folha torna-se perfurada. O aumento do número de lesões e o aumento da área lesionada induzem à completa senescência da folha e, à uma redução significativa da área foliar e, conseqüente, diminuição da produtividade. A resistência genética é o preferencial método de controle, no entanto, em experimentos realizados por Marcuzzo et al. (Horticultura brasileira, v.33, n.1, p.106-109, 2015) não constataram resistência à doença entre os principais genótipos comercializados no Brasil. O arranjo espacial (espaçamento) de plantas é indicado em várias culturas, com a finalidade de aumentar a insolação e arejamento interno as plantas com o intuito de diminuir o molhamento foliar, fundamental para o processo de infecção do patógeno. Como se desconhece este efeito na cultura da beterraba, esse trabalho teve como objetivo avaliar a interação de diferentes espaçamentos com o controle da cercosporiose em beterraba. O experimento foi instalado na Epagri, Estação Experimental de Ituporanga (Região do Alto Vale do Itajaí, SC) em 2014 (semeadura em 26/03/2014 e colheita em 11/08/2014) e em 2015 (semeadura em 01/12/2014 e colheita em 19/03/2015), utilizandose o híbrido Boro. O delineamento utilizado foi em blocos casualizados com seis espaçamentos e quatro repetições. As densidades de plantas e espaçamentos correspondentes foram: 500.000 plantas. ha $^{-1}(20 \mathrm{~cm}$ entre filas x $10 \mathrm{~cm}$ entre plantas); 400.000 (20 cm x 12,5 cm); 333.333 $(30 \mathrm{~cm} \times 10 \mathrm{~cm}) ; 266.666(30 \mathrm{~cm} \times 12,5 \mathrm{~cm}) 250.000(40 \mathrm{~cm} \times 10 \mathrm{~cm})$ e 200.000 (40 cm x 12,5 cm). Cada parcela foi constituída por cinco linhas de plantio e área total de $3 \mathrm{~m}^{2}(2,0 \mathrm{~m} \times 1,5 \mathrm{~m})$ com intervalo de $0,5 \mathrm{~m}$ entre parcelas. Semanalmente foi avaliada a severidade da cercosporiose em cinco plantas marcadas aleatoriamente dentro de cada repetição com auxílio de escala diagramática (May de Mio et al., Scientia agraria, n.1, p.331-337, 2008). Os dados de severidade foram integralizados e calculados pela área abaixo da curva de progresso da doença (AACPD) através da fórmula: AACPD $=\sum[(y 1+y 2) / 2] *(t 2-t 1)$, onde $y 1$ e $y 2$ que refere-se a duas avaliações sucessivas da intensidade da doença realizadas nos tempos $t 1$ e $t 2$, respectivamente (Campbell \& Madden, Introduction to plant disease epidemiology, 1990). Avaliou-se a taxa de infecção proposta por Vanderplank (Plant disease: epidemics and control, 1963). Na colheita, as plantas avaliadas foram pesadas e convertidas para produtividade em kg.ha ${ }^{-1}$. As médias obtidas da AACPD, severidade final (\%), taxa de infecção $(r)$ e da produtividade $\left(\mathrm{kg} \cdot \mathrm{ha}^{-1}\right)$ foram submetidos à análise estatística pelo software SASMAgri (Canteri et al., Revista brasileira de agrocomputação, v.1, n.1, p.18-24, 2001) para constatar o efeito do espaçamento e controle da doença. AAACPD e severidade final não foram significativas nos dois ciclos da cultura (Tabela 1). A maior diferença na severidade final entre os ciclos foi no espaçamento $30 \mathrm{~cm}$ x 12,5 cm com diferença de apenas 1,32\%. Bălău (Lucrăriştiinţifice, v.54, n.2, p.199-202, 2011) também constatou pequenas diferenças (entre 2,0 e 2,4\%) na severidade final em beterraba açucareira. $\mathrm{O}$ espaçamento influencia diretamente na taxa de infecção (Zadoks \& Schein, Epidemiology and plant disease management, 1979), porém nesse trabalho não foi significativa entre os espaçamentos nos dois ciclos de avaliação (Tabela 1). Kaiser et al. (Journal of phytopathology, v.158, n.4, p.296-306, 2010) também não verificaram diferenças no progresso da cercosporiose na beterraba açucareira e isso esta diretamente relacionado a taxa de infecção,

Tabela 1. Valores da área abaixo da curva do progresso da doença (AACPD), severidade final (\%), taxa de infecção $(r)$ e produtividade (Kg.ha-1) na avaliação de diferentes espaçamentos no controle da cercosporiose da beterraba. Epagri/E.E Ituporanga 2014-2015

\begin{tabular}{|c|c|c|c|c|c|c|c|c|}
\hline \multirow[t]{2}{*}{$\begin{array}{l}\text { Espaçamento } \\
(\mathrm{cm})\end{array}$} & \multicolumn{2}{|c|}{ AACPD } & \multicolumn{2}{|c|}{ Severidade final (\%) } & \multicolumn{2}{|c|}{$\begin{array}{c}\text { Taxa de infecção } \\
\text { (r) }\end{array}$} & \multicolumn{2}{|c|}{ Produtividade (Kg.ha $\left.{ }^{-1}\right)$} \\
\hline & 2014 & 2015 & 2014 & 2015 & 2014 & 2015 & 2014 & 2015 \\
\hline $20 \times 12,5$ & 677,26 & 409,00 & 16,20 & 16,74 & 0,066 & 0,076 & 25.862 & 5.330 \\
\hline $30 \times 10$ & 684,31 & 440,44 & 16,41 & 17,52 & 0,070 & 0,072 & 23.539 & 8.280 \\
\hline $30 \times 12,5$ & 669,49 & 426,22 & 15,91 & 17,23 & 0,073 & 0,071 & 28,711 & 10.050 \\
\hline $40 \times 12,5$ & 654,92 & 419,67 & 16,29 & 16,74 & 0,072 & 0,072 & 32.749 & 10.360 \\
\hline C.V $(\%)$ & 6,80 & 10,76 & 5,18 & 5,02 & 14,15 & 12,90 & 28,90 & 33,54 \\
\hline
\end{tabular}

ns: não significativo pelo teste F; C.V: coeficiente de variação. 
que também não diferiria se fosse avaliado em diferentes condições de cultivo conforme avaliado por Gaurilčikienè et al. (Biologija, v.4, p.54-59, 2006) em beterraba açucareira. Quanto a produtividade também não houve diferença nas duas avaliações (Tabela 1). No entanto, constatou-se que no segundo ano de avaliação a produtividade foi inferior, possivelmente decorrente do período de condução, que foi no verão, o qual propicia maior intensidade da doença e conseqüente senescência precoce das folhas com reflexo na produtividade. Quando se compara a produtividade no espaçamento $20 \mathrm{~cm}$ x10 $\mathrm{cm}$ obteve se redução por causa da doença em $49 \%$ e $76 \%$ no primeiro e segundo ano respectivamente em relação ao trabalho feito por Corrêa et al. (Horticultura brasileira, v.32, n.1, p.111-114, 2014). Mediante aos resultados obtidos para as condições de plantio, nenhum espaçamento mostrou-se eficiente no controle da cercoporiose da beterraba na região do Alto Vale do Itajaí, SC.

\section{Agradecimentos}

Ao CNPq e à FAPESC (chamada pública do acordo de cooperação $\mathrm{CNPq}+\mathrm{FAPESC}$ - Repensa) pelo apoio financeiro recebido para condução deste trabalho e pela concessão de bolsas ATP - B. 